\title{
PEMBUATAN TURBIN ANGIN SUDU TIPE FLAT BERLAPIS TIGA
}

\author{
Sahid, Teguh Harijono Mulud. \\ Program Studi Teknik Konversi Energi,Jurusan Teknik Mesin, Politeknik Negeri Semarang \\ Jl. Prof. H. Sudarto, SH Tembalang, Semarang, 50061, Indonesia \\ Email: iqbal.yudianto1995@gmail.com
}

\begin{abstract}
ABSTRAK
Turbin angin adalah alat yang dapat mengkonversi energi kinetik dari angin menjadi energi lisrik. Konsep sudu berlapis belum pernah diteliti ataupun dikembangkan dengan turbin angin sumbu horizontal. Pengembangan berbagai macam turbin angin mempunyai tujuan untuk membuat turbin angin yang sesuai dengan keadaan potensi angin Indonesia dan mempunyai nilai Cp yang tinggi. Langkah-langkah yang dilakukan dalam Tugas Akhir meliputi observasi, perancangan dan pembuatan turbin, pengujian karakteristik turbin pelton yang sudah dibuat. Hasil uji karakteristik pada kecepatan angin $3 \mathrm{~m} / \mathrm{s}$ Cp terbesar yang dihasilkan oleh turbin angin tipe flat berlapis dengan sudut sudu $8^{\circ}$ adalah 1,34\% dan nilai TSR terbesar adalah 3,74. Sedangkan pada kecepatan angin $4 \mathrm{~m} / \mathrm{s}$ dan $5 \mathrm{~m} / \mathrm{s}$ Cp terbesar yang dihasilkan oleh turbin angin sudu tipe flat berlapis tiga dengan sudut sudu $10^{\circ}$ dan $15^{\circ}$ adalah 0,78\% dan 0,37\% serta TSR terbesar adalah 3,58 dan 3,19.
\end{abstract}

Kata kunci: turbin angin, sudu tiga, berlapis tiga

\section{PENDAHULUAN}

Turbin angin sumbu horizontal dengan letak poros searah aliran angin yang ditangkap oleh sudu. Masing-masing turbin angin ini memiliki karakteristik serta Coefisien of Power yang berbeda-beda. Bahan yang digunakan untuk pembuatan sudu juga mepengaruhi karakteristik serta Coefisien of Power sebuah TASH. Umumnya bahan yang digunakan untuk membuat sudu-sudu turbin angin adalah fiber (NACA) dan plat galvanis (tipe flat). Banyak penelitian serta pengembangan yang dilakuan pada desain TASH. Pengembangan banyak dilakukan pada jumlah sudu, bentuk sudu, serta bahan untuk membuat sudu. Namun belum ada penelitian mengenai TASH yang bertumpuk (berlapis). Dengan sudu turbin yang dibuat banyak tingkat dapat meningkatkan Coefisien of Power.

\section{TINJAUAN PUSTAKA}

\section{Potensi Energi Angin di Indonesia}

Seperti pada umumnya negara tropis, kecepatan angin rata-rata di Indonesia terbilang kecil hanya sekitar 3-5 m/s. Supaya layak secara komersil, kecepatan angin yang diperlukan untuk turbin angin berada dalam 36 kisaran $5-6 \mathrm{~m} / \mathrm{s}$ pada ketinggian pusat $10 \mathrm{~m}$. Hanya sedikit daerah di Indonesia dengan kecepatan angin cukup besar.

\section{Turbin Angin Sumbu Horizontal}

Turbin angin sumbu horizontal merupakan turbin angin yang memiliki sumbu putar terletak sejajar dengan permukaan tanah, selain itu sumbu putar rotornya selalu searah dengan arah angin. Kelebihan dari turbin angin sumbu horizontal adalah towernya yang tinggi memungkinkan untuk mendapatkan angin dengan kekuatan yang lebih besar, Coefisien of Power lebih tinggi karena sudu selalu bergerak tegak lurus terhadap arah angin.

\section{Konsep Tiga Sudu}

Turbin angin dengan konsep ini lebih mudah setimbang dibandingkan konsep satu sudu dan dua sudu,

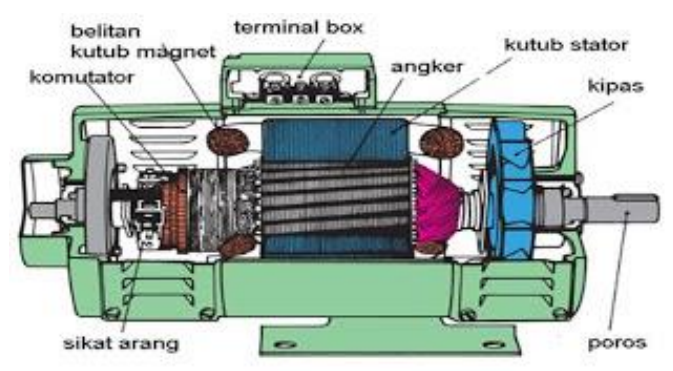


konsep sudu ini juga merupakan konsep yang paling umum digunakan dan dikomersilkan. Konsep tiga sudu memiliki kemampuan menangkap angin secara efektif.

\section{Tip speed ratio}

Tip speed ratio (rasio kecepatan ujung) adalah rasio kecepatan ujung rotor terhadap kecepatan angin bebas. Untuk kecepatan angin nominal yang tertentu, tip speed ratio akan berpengaruh pada kecepatan putar rotor. Turbin angin tipe lift akan memiliki tip speed ratio yang relatif lebih besar dibandingkan dengan turbin angin tipe drag.

Generator DC merupakan sebuah perangkat mesin listrik dinamis yang mengubah energi mekanis menjadi energi listrik. Generator DC menghasilkan arus DC / arus searah.

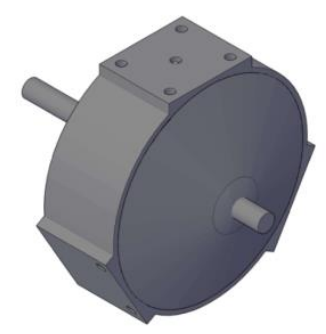

Gambar 1. Generator DC

\begin{tabular}{|l|l|}
\hline $\begin{array}{l}\text { Putaran } \\
\text { generator }\end{array}$ & $5420 \mathrm{rpm}$ \\
\hline Tegangan & 24 Volt \\
\hline Arus & $\begin{array}{l}0.033 \\
\text { Ampere }\end{array}$ \\
\hline
\end{tabular}

Untuk pertimbangan dalam membuat turbin angin diperlukan beberapa parameter yaitu Tip Speed Ratio (TSR) dan jumlah blade. Perbandingan koefisien drag dan koefisien lift $(\mathrm{Cd} / \mathrm{Cl})$ sebagai dasar untuk pemilihan jumlah blade turbin angin diperlukan grafik pengaruh jumlah sudu dan perbandingan daya dorong.

\section{KEGIATAN PELAKSANAAN Tahap Rancangan}

Tahap perancangan ini meliputi penentuan ukuran dimensi turbin dan kelengkapannya.

\section{Sudu Dan Pemegang Sudu}

Dimensi sudu turbin adalah panjang 300 $\mathrm{mm}$, lebar $100 \mathrm{~mm}$ dan tebal plat $0,8 \mathrm{~mm}$. pemegang sudu memiliki dimensi panjang $300 \mathrm{~mm}$, lebar $20 \mathrm{~mm}$ dan tebal $2 \mathrm{~mm}$

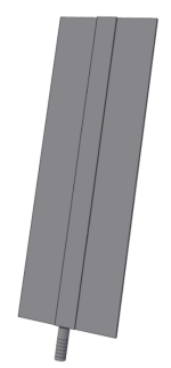

Gambar 2. Sudu dan pemegang sudu

2. Piringan Sudu

Piringan sudu terbuat dari pipa galvanis dengan diameter $140 \mathrm{~mm}$, memiliki panjang $180 \mathrm{~mm}$ ketebalan $3 \mathrm{~mm}$.

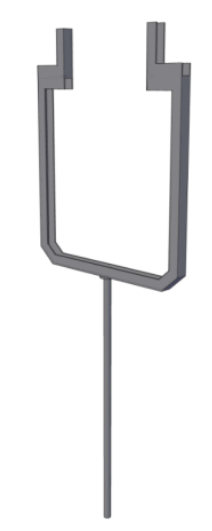

Gambar 3. Piringan turbin

3. Poros turbin

Poros dibuat dari besi pejal dengan diameter $16 \mathrm{~mm}$ panjang $290 \mathrm{~mm}$.
4. Generator
Spesifikasi generator 


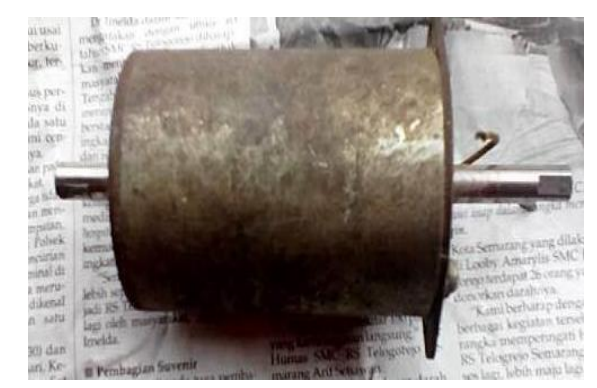

Gambar 4. Generator

\section{Gear}

Gear yang digunakan pada turbin adalah turbin tipe kerucut lurus yang dipasang saling tegak lurus, gear menggunakan rasio 2 : 1 .

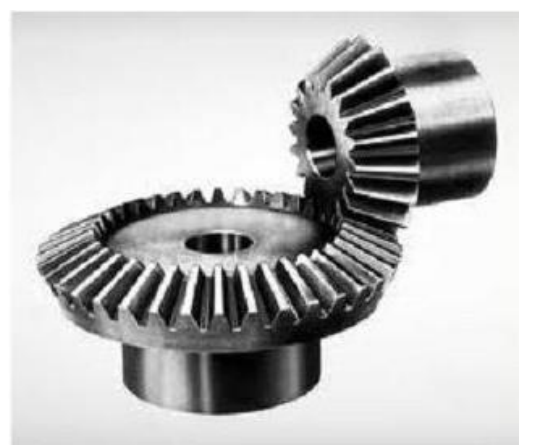

Gambar 5. Gear

6. Kerangka

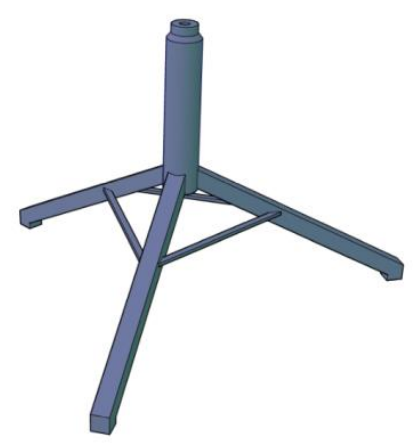

$6 . a$

6.b

Gambar 6.a Kerangka Atas; Gambar 6.b Kerangka Bawah

\section{Tahap Pengujian Alat}

Tahap pengujian meliputi dilakukan untuk mendapatkan data meliputi putaran turbin, tegangan yang dihasilkan, dan arus yang mengalir yang digunakan untuk mencari karakteristik turbin angin. Prosedur pengujiannya adalah sebagai berikut:

1. Mempersiapkan semua peralatan uji yang akan digunakan baik sebagai komponen pendukung dan pengukuran seperti blower, voltmeter, amperemeter, tachometer dan beban lampu.

2. Merangkai alat ukur voltmeter, amperemeter, beban dan generator.

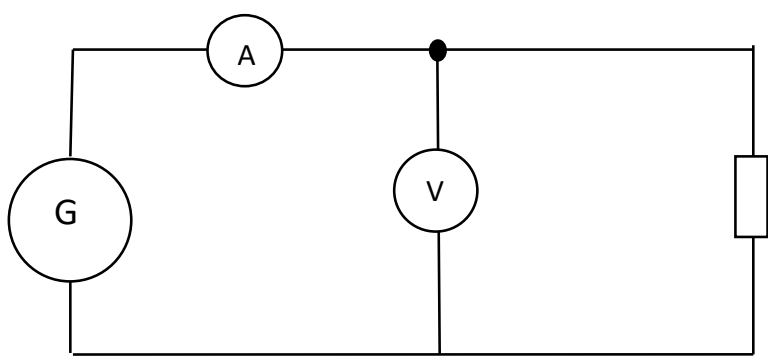

Gambar 7. Gambar Rangkaian Pengujian

3. Mengatur variasi sudut sudu yang sudah ditentukan $\left(6^{\circ}, 8^{\circ}, 10^{\circ}, 15^{\circ}, 30^{\circ}\right.$, dan $45^{\circ}$ )

4. Mengatur jarak blower dengan turbin untuk mendapatkan kecepatan angin tertentu yang diukur menggunakan anemometer.

5. Meng-On kan blower.

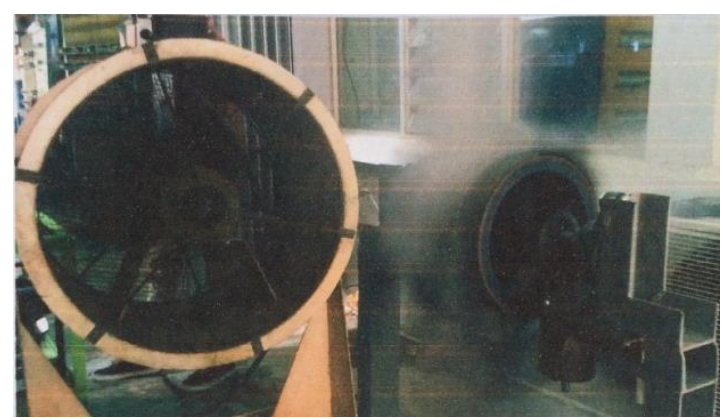

Gambar 8. Blower 
6. Memulai dengan beban nol pada pengujian awal.

7. Mengukur putaran yang dihasilkan dengan tachometer.

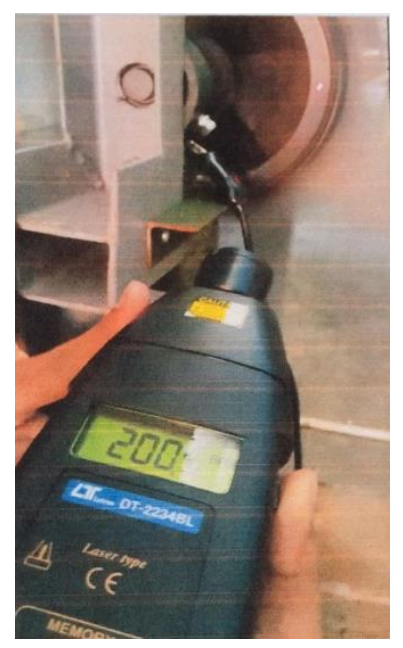

Gambar 9. Tachometer

8. Membaca tegangan yang dihasilkan dengan voltmeter

9. Membaca arus listrik yang mengalir dengan ampere meter dalam setiap pembebanan.

10. Dengan cara yang sama dari langkah 7 sampai 9 sampai pembebanan 10 beban lampu

11. Melakukan langkah yang sama pada setiap variasi sudut sudu dengan 5 kali variasi kecepatan angin.

12. Merapikan peralatan setelah selesai pengujian.

13. Mengolah data, membuat table untuk dibuat dalam bentuk kurva karakteristik turbin.

\section{HASIL DAN PEMBAHASAN \\ Hasil Rancangan Turbin Angin}

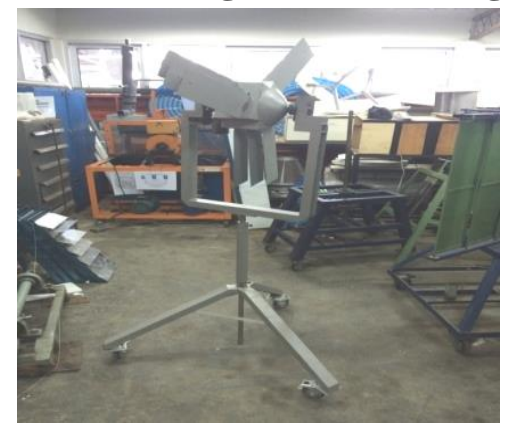

Gambar 10. Hasil Rancangan Turbin Angin

\section{Data Pengujian}

Setelah dilakukan pengujian maka didapatkan data-data sebagai berikut:

Tabel 1. Sudut Sudu $45^{0}$ Kecepatan Angin 3 $\mathrm{m} / \mathrm{s}$

\begin{tabular}{|l|l|l|l|}
\hline \multirow{2}{*}{ No. } & Putaran & Tegangan & Arus \\
\cline { 2 - 4 } & rpm & Volt & Ampere \\
\hline 1. & 128 & 1,2 & 0 \\
\hline 2. & 125 & 0,5 & 0,014 \\
\hline 3. & 124 & 0,2 & 0,02 \\
\hline 4. & 122 & 0,1 & 0,025 \\
\hline 5. & 115 & 0,1 & 0,025 \\
\hline 6. & 115 & 0,1 & 0,023 \\
\hline 7. & 115 & 0,1 & 0,024 \\
\hline 8. & 115 & 0,1 & 0,024 \\
\hline 9. & 115 & 0,1 & 0,024 \\
\hline 10. & 115 & 0,1 & 0,024 \\
\hline 11. & 115 & 0,1 & 0,024 \\
\hline
\end{tabular}

Tabel 2. Data Hasil Perhitungan

\begin{tabular}{|l|l|l|l|l|}
\hline \multirow{2}{*}{ No. } & \multirow{2}{*}{$\begin{array}{l}\text { Tip } \\
\text { Speed } \\
\text { Ratio }\end{array}$} & $\begin{array}{l}\text { Daya } \\
\text { Kinetik } \\
\text { Angin }\end{array}$ & $\begin{array}{l}\text { Daya } \\
\text { Listrik }\end{array}$ & $\begin{array}{l}\text { Coefisien } \\
\text { of Power }\end{array}$ \\
\hline 1. & 1,4 & 5,21 & Watt & $\%$ \\
\hline 2. & 1,4 & 5,21 & 0,007 & 0,13 \\
\hline 3. & 1,4 & 5,21 & 0,004 & 0,07 \\
\hline 4. & 1,36 & 5,21 & 0,0025 & 0,04 \\
\hline 5. & 1,28 & 5,21 & 0,0025 & 0,04 \\
\hline 6. & 1,28 & 5,21 & 0,0023 & 0,04 \\
\hline 7. & 1,28 & 5,21 & 0,0024 & 0,04 \\
\hline 8. & 1,28 & 5,21 & 0,0024 & 0,04 \\
\hline 9. & 1,28 & 5,21 & 0,0024 & 0,04 \\
\hline 10. & 1,28 & 5,21 & 0,0024 & 0,04 \\
\hline 11. & 1,28 & 5,21 & 0,0024 & 0,04 \\
\hline
\end{tabular}

\section{Perhitungan}

Berdasarkan data hasil pengujian yang diperoleh seperti pada tabel hasil pengujian maka dapat dihitung besarnya tip speed ratio, daya kinetik, daya listrik, dan Coefisien of Power.

Contoh perhitungan diambil dari tabel data pengujian pada Tabel 1 data pengujian turbin angin sudu tipe flat berlapis tiga sudut 
sudu $45^{0}$ kecepatan angin $3 \mathrm{~m} / \mathrm{s}$ dengan data sebagai berikut :

1. Kecepatan angin $(\mathrm{v})=3 \mathrm{~m} / \mathrm{s}$

2. Putaran Poros $(\mathrm{n})=125 \mathrm{rpm}$

3. $\rho$ udara $=1,184 \mathrm{~kg} / \mathrm{m}^{3}$

4. Luasan Sapuan Turbin $(A)=0,64 \mathrm{~m}^{2}$

5. Tegangan $(\mathrm{V})=0,5$ Volt

6. Arus $(\mathrm{I})=0,014$ Ampere

7. Beban nominal lampu pijar $=10 \mathrm{Watt}$

Untuk data selanjutnya dapat dihitung dengan menggunakan persamaan yang sama. Perhitungan tip speed ratio sesuai dengan persamaan yaitu:

$$
\begin{aligned}
\lambda & =\frac{\omega r}{v} \\
& =\frac{\pi \mathrm{d} \frac{n}{60}}{u} \\
& =\frac{3,14 \cdot 0,64 \cdot \frac{125}{60}}{3} \\
& =1,39
\end{aligned}
$$

Perhitungan daya kinetik sesuai dengan persamaan yaitu :

$$
\begin{aligned}
P_{\text {kin }} & =\frac{1}{2} \cdot \rho \text { udara } \cdot \mathrm{A} \cdot \mathrm{v}^{3} \\
& =\frac{1}{2} \cdot 1,184 \cdot 0,64 \cdot(3)^{3} \\
& =5,21 \text { Watt }
\end{aligned}
$$

Perhitungan daya generator sesuai dengan persamaan yaitu :

$$
\begin{aligned}
\mathrm{P}_{\mathrm{g}} & =\mathrm{V} . \mathrm{I} \\
& =0,5 \cdot 0,014 \\
& =0,07 \text { Watt }
\end{aligned}
$$

Perhitungan Coefisien of Power sesuai dengan persamaan yaitu :

$$
\begin{aligned}
C p & =\frac{P g}{P \text { kin }} \times 100 \% \\
& =\frac{0,07}{5,21} \times 100 \% \\
& =0.134 \%
\end{aligned}
$$

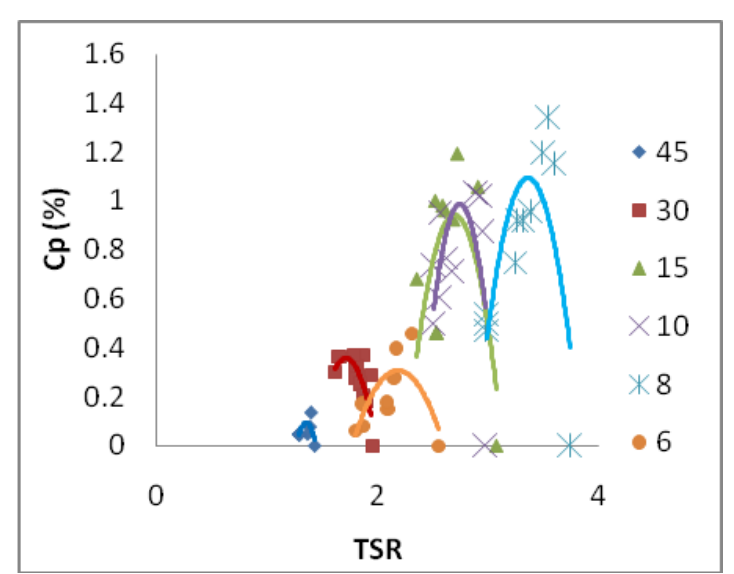

Gambar 11. Karakteristik Cp terhadap TSR pada Kecepatan Angin 3 m/s.

\section{Analisa data}

Berdasarkan gambar 4.2 merupakan kurva yang menggambarkan tentang TSR terhadap $C p$. Nilai TSR berbanding lurus dengan besarnya putaran turbin. Pada kecepatan angin $3 \mathrm{~m} / \mathrm{s}$ nilai TSR tertinggi untuk masing-masing sudut sudu adalah ada sudut kemiringan sudu $45^{\circ}$ nilai TSR paling besar yaitu 1,5; pada sudut kemiringan sudu $30^{0}$ nilai TSR paling besar yaitu 2; pada sudut kemiringan sudu $15^{0}$ nilai TSR paling besar yaitu 3,05; pada sudut kemiringan sudu $10^{0}$ nilai TSR paling besar yaitu 3; pada sudut kemiringan sudu $8^{0}$ nilai TSR paling besar yaitu 3,05; pada sudut kemiringan sudu $6^{0}$ nilai TSR paling besar yaitu 2,5 .

Dari trend kurva $C p$ pada gambar 11 diketahui bahwa $C p$ sudah dapat mencapai titik optimum, dimana $C p$ turbin mengalami penurunan setelah mencapai titik puncak. $C p$ paling baik pada kecepatan $3 \mathrm{~m} / \mathrm{s}$ adalah pada sudut $8^{0}$. Hal ini dikarenakan semakin kecil sudut sudu turbin maka plane area sudu yang berinteraksi dengan aliran angin menjadi lebih kecil dan gaya angkat semakin besar, sehingga putarannya besar.

\section{Kesimpulan}

1. Turbin angin sudu tipe flat berlapis memiliki 3 buah sudu di setiap lapis dengan menggunakan bahan galvanis yang dapat diubah sudut kemiringan sudunya. Dimensi sudu, panjang : 300 
$\mathrm{mm}$; lebar : $100 \mathrm{~mm}$; tebal : $8 \mathrm{~mm}$. Dimensi piringan sudu, diameter : 140 $\mathrm{mm}$; panjang: $180 \mathrm{~mm}$; tebal: $3 \mathrm{~mm}$. Dimensi kerangka atas, panjang : 607; $\mathrm{mm}$ lebar : $550 \mathrm{~mm}$; profil plat $\mathrm{U}$ : 50x40 mm. Dimensi kerangka bawah, tinggi : $770 \mathrm{~mm}$; dimensi kaki : $530 \mathrm{~mm}$ $\mathrm{x} 48 \mathrm{~mm}$.

2. Hasil uji karakteristik pada kecepatan angin $3 \mathrm{~m} / \mathrm{s} \mathrm{Cp}$ terbesar yang dihasilkan oleh turbin angin tipe flat berlapis dengan sudut sudu $8^{\circ}$ adalah $1,34 \%$ dan nilai TSR terbesar adalah 3,74. Sedangkan pada kecepatan angin $4 \mathrm{~m} / \mathrm{s}$ dan $5 \mathrm{~m} / \mathrm{s}$ Cp terbesar yang dihasilkan oleh turbin angin sudu tipe flat berlapis tiga dengan sudut sudu $10^{\circ}$ dan $15^{\circ}$ adalah $0,78 \%$ dan $0,37 \%$ serta TSR terbesar adalah 3,58 dan 3,19

3. Semakin besar kecepatan angin maka sudut sudu dengan nilai $\mathrm{Cp}$ terbaik semakin besar dari sudut sudu pada kecepatan angin sebelumnya

\section{DAFTAR PUSTAKA}

Leysen, E.H.1983.Introduction to Wind

Energy. Consultancy Services Wind

Energy Developing Countries.

Belanda.

Hau,Erich.2006. Wind Turbines

"Fundamental, Technologies,

Application, Economics $2^{\text {nd }}$

edition.Springer.

Rizkiyono,Dwi,dkk.2015.Rancang Bangun

Turbin Angin Multiblade Dengan

Generator Menggunakan Motor

Sepeda Listrik Sebagai Pembangkit

Listrik Tenaga Bayu.Tugas

Akhir.Semarang.Jurusan Teknik Mesin

Polines.

Satriani, Galih Putra dkk.2015.Modifikasi

Dan Kinerja Turbin Angin Sudu Flat

Bingkai Berbasis Trapesium.Tugas
Akhir.Semarang.Jurusan Teknik Mesin

Polines.

Kunto.2014."Dasar Tenaga Elektrik"

Maede, Russel L.Foundation of Electronic 